\title{
Effect of Piperine on Skin Permeation of Curcumin from a Bacterially Derived Cellulose-Composite Double-Layer Membrane for Transdermal Curcumin Delivery
}

\author{
Chutima Jantarat ${ }^{1,2, *}$, Pornpak Sirathanarun ${ }^{2}$, Somruedee Boonmee ${ }^{2}$, Wanida Meechoosin ${ }^{2}$ and \\ Husna Wangpittaya ${ }^{2}$ \\ 1 Drug and Cosmetics Excellence Center, Walailak University, Thasala, Nakhon Si Thammarat 80160, Thailand \\ 2 School of Pharmacy, Walailak University, Thasala, Nakhon Si Thammarat 80160, Thailand; \\ spornpak@wu.ac.th (P.S.); somruedee.b@dmsc.mail.go.th (S.B.); akirarx27@gmail.com (W.M.); \\ husna_w42@hotmail.com (H.W.) \\ * Correspondence: chutima.ja@wu.ac.th; Tel.: +66-756-728-30
}

Received: 17 August 2018; Accepted: 8 September 2018; Published: 13 September 2018

\begin{abstract}
Curcumin is a naturally occurring substance with various pharmacological activities. It has not been developed as a drug because of its low bioavailability due to its low solubility and absorption. Piperine is a natural enhancer that is popularly used to increase the absorption of curcumin in oral applications; however, it has not been applied for transdermal curcumin delivery. This study aims to develop a transdermal curcumin delivery system using piperine as a skin permeation enhancer in the form of composite double-layer membrane; the upper layer consisted of curcumin and the lower layer consisted of piperine. The amount of curcumin was fixed, but the amount of piperine varied at three levels from $1.96 \%$ to $7.41 \%$. The composite membrane had moderate mechanical strength (15-22 MPa) with a good swelling degree $(\sim 435 \%)$. From an in vitro skin permeation study, piperine had the effect to increase the permeation of curcumin. The permeation rate was related to the amount of piperine. The composite membrane containing piperine at $7.41 \%$ could increase the permeation rate of curcumin by about 1.89 times compared with non-piperine contained membrane. Bacterially-derived cellulose containing curcumin and piperine may have the potential for transdermal curcumin delivery in order to improve curcumin's bioavailability.
\end{abstract}

Keywords: curcumin; piperine; bioenhancer; bacterially derived cellulose; transdermal drug delivery

\section{Introduction}

The use of herbal medicines and natural products is very popular today and is expected to increase continuously every year because people concern about the safety of using drugs derived from synthetic chemicals. Nowadays, many herbs are made into medicines and more health products because they are derived from natural and have unique properties. Turmeric (Curcuma longa) is one of the most popular herbs for treating various maladies such as abdominal pain, colic, and flatulence [1]. The primary substance found in turmeric is curcuminoid. Curcumin, a polyphenolic compound, is the main constituent of curcuminoids, constituting about 77\% of curcuminoid content [2]. Several studies have confirmed that curcumin has antioxidant, anti-inflammatory, antibacterial, antifungal, antidiabetic, antiproliferative, and antitumor activities [3-5].

Although curcumin has a good and varied pharmacological activity, it has not developed as a drug because of a low bioavailability. In vitro studies revealed that the concentration of curcumin that could give the desired activity was about $3.6 \mathrm{mg} / \mathrm{mL}$. However, in vivo studies in humans and 
animals showed that the concentration of curcumin detected in blood was very low, about $0.8 \mu \mathrm{g} / \mathrm{mL}$, even when administered in very high doses (12 g) [6]. This shows that the amount of curcumin that can be transported to the target organs for effective treatment is quite difficult. This is because the chemical structure of curcumin is hydrophobic polyphenolic compound which has a solubility as low as $\sim 1 \mu \mathrm{g} / \mathrm{mL}$ [7]. In a Caco-2 cell absorption study, curcumin was classified in BCS class IV (low solubility and low permeability) [8]. Moreover, curcumin undergoes extensive first pass metabolism [9]. These problems have led to ineffective curcumin treatment. Transdermal curcumin delivery may be an alternative method of curcumin treatment, because it can avoid first pass metabolism.

Curcumin delivery systems have been developed in various forms, including nanosuspension, nanoemulsion, nanoparticles, liposomes, ethosomes, and lipid base systems [10-13]. An absorption enhancer was introduced into the systems in order to increase bioavailability. Currently, the use of natural enhancer (bioenhancer) has gained attention for herbal drug delivery [14]. Piperine is the first natural enhancer discovered in 1979 [15]. It is an alkaloid that causes a spicy taste in pepper (Piper nigrum) and longan (Piper Longum). Piperine can improve the oral absorption of many drugs including curcumin [16-22]. The bioenhancing effect of piperine has been proposed in several mechanisms, for example, by acting on drug metabolizing enzymes, by inducing alterations in membrane dynamics, by affecting blood supply, and by enhancing drug transport [14,23,24]. In human studies, curcumin in combination with piperine at a weight ratio of 200:1 can increase oral bioavailability of curcumin up to $2000 \%$ [25]. In recent years, it has been reported that piperine was also used as transdermal enhancer and can enhance the skin permeation of aceclofenac and repaglinide by about $2-8$ times [26,27]. The mechanism might be involved in the partial extraction of stratum corneum lipids, interaction with keratin of stratum corneum, and tight junction protein disruption [28]. It has been proven, using quantum chemical and molecular docking techniques, that piperine can enhance curcumin's bioavailability through an intercalation complex of piperine with curcumin via intermolecular forces between two stacking layers of curcumin [29].

In this study, the transdermal curcumin delivery system was prepared from bacterially derived cellulose in a double layer using hydroxypropyl- $\beta$-cyclodextrin and piperine as a solubilizer and bioenhancer, respectively. The effect of piperine on skin permeation of curcumin was investigated in vitro with mouse skin.

\section{Materials and Methods}

\subsection{Materials}

Curcumin and piperine were purchased from Sigma-Aldrich (St. Louis, MO, USA). Hydroxypropyl- $\beta$-cyclodextrin was obtained from Wacker Chemie GmbH (Munich, Germany). Swollen bacterially derived cellulose was taken from the local market (Songkhla, Thailand) and thoroughly washed with distilled water until a neutral $\mathrm{pH}$ was achieved before use. All other chemicals and solvents were of analytical grade and used as received.

\subsection{Preparation of a Bacterially Derived Cellulose-Composite Membrane}

A bacterially derived cellulose-composite membrane as a double layer containing curcumin in the upper layer and piperine in the lower layer was prepared by the casting and solvent evaporation method. The amount of curcumin was fixed, but the amount of piperine varied from $1.96 \%$ to $7.41 \%$. The composition of composite membranes is shown in Table 1. First, the swollen bacterially derived cellulose (BC) was blended in a juice blender (HR2108, Philips, Netherlands) to achieve a BC slurry. Piperine $(4,8$, or $16 \mathrm{mg})$ was dissolved with $50 \% v / v$ ethanol $(5 \mathrm{~mL})$ before being added to the BC slurry $(15 \mathrm{~g})$ and mixed until homogeneous. The mixture was cast as a membrane in a Petri dish $(10 \mathrm{~cm}$ diameter), which was padded with aluminum foil to prevent the membrane from sticking to the glass. The Petri dish was sonicated for $5 \mathrm{~min}$ to remove bubbles, and the solvent was evaporated in a hot air oven (UF 110, Memmert GmbH + Co. KG, Schwabach, Germany) at $60^{\circ} \mathrm{C}$ for $2 \mathrm{~h}$ to obtain a dried 
piperine-cellulose-composite membrane as the lower layer of the composite membrane. The thickness of composite membrane was measured with Vernier calipers (Mitutoyo Co., Kawasaki, Japan).

Next, the upper layer containing curcumin and hydroxypropyl- $\beta$-cyclodextrin (HPBCD) at a weight ratio of 1:1 was prepared and placed onto the dried lower layer obtained earlier. HPBCD $(200 \mathrm{mg})$ was dissolved with 50\% v/v ethanol $(10 \mathrm{~mL})$, and curcumin $(200 \mathrm{mg})$ was added and mixed until a clear solution was obtained. The solution was then added into another part of the BC slurry (15 g) and mixed until homogeneous. The mixture was cast as a membrane onto the dried piperine-cellulose-composite membrane in a Petri dish, sonicated for $5 \mathrm{~min}$, and the solvent was evaporated in a hot air oven (UF 110, Memmert GmbH + Co. KG, Schwabach, Germany) at $60{ }^{\circ} \mathrm{C}$ for $4 \mathrm{~h}$ to obtain a dried composite membrane as a double layer. The obtained composite membrane (dimension of $78.57 \mathrm{~cm}^{2}$ ) was peeled off the aluminum foil and kept in a desiccator until used.

The controlled composite membrane (CCM) and the blank composite membrane (BCM) were also prepared in the same method as described above but without piperine and without both curcumin and piperine, respectively. In a preliminary study, the composite membranes containing various amount of curcumin $(100,150$, and $200 \mathrm{mg})$ and a fixed amount of piperine $(8 \mathrm{mg})$ were prepared to evaluate their physical properties and to find the optimum amount of curcumin loaded into the composite membrane.

Table 1. Types and compositions of bacterially derived cellulose-composite membranes with a size of $78.57 \mathrm{~cm}^{2}$.

\begin{tabular}{ccc}
\hline \multirow{2}{*}{ Type of Composite Membrane } & \multicolumn{2}{c}{ Composition (mg) } \\
\cline { 2 - 3 } & Curcumin & Piperine \\
\hline Blank composite membrane (BCM) & - & - \\
Controlled composite membrane & 200 & - \\
(CCM) & 100 & 8 \\
CM100:8 & 150 & 8 \\
CM150:8 & 200 & 4 \\
CM200:4 & 200 & 8 \\
CM200:8 & 200 & 16 \\
CM200:16
\end{tabular}

\subsection{Physical Property Test}

\subsubsection{Swelling}

The swelling property of composite membranes containing different amounts of curcumin but a fixed amount of piperine (CM100:8, CM150:8, and CM200:8) was evaluated in comparison with a blank composite membrane (BCM). The composite membranes were cut into $1 \times 1 \mathrm{~cm}$ and soaked in distilled water $(5 \mathrm{~mL})$ at $25 \pm 1{ }^{\circ} \mathrm{C}$ for $6 \mathrm{~h}$. The weights of composite membrane initially $\left(\mathrm{m}_{\mathrm{i}}\right)$ and when fully swollen $\left(\mathrm{m}_{\mathrm{s}}\right)$ were used to calculate the swelling degree $(\%)$ using the equation

$$
\text { Swelling degree }(\%)=\frac{\left(m_{s}-m_{i}\right)}{m_{i}} \times 100
$$

\subsubsection{Tensile Strength}

The tensile strength $(\sigma)$ of composite membranes containing different amounts of curcumin (CM100:8, CM150:8, and CM200:8), but a fixed amount of piperine was evaluated in comparison with a blank composite membrane (BCM). The composite membranes were prepared as a dumbbell-shaped specimen. The prepared specimen was tested using universal testing machine with a crosshead speed of $1 \mathrm{~mm} / \mathrm{min}$ at $25 \pm 1{ }^{\circ} \mathrm{C}, 50 \% \mathrm{RH}$. The tensile strength was then calculated using the equation 


$$
\sigma=\frac{P_{\max }}{\mathrm{A}}
$$

where $\mathrm{P}_{\max }$ and $\mathrm{A}$ are the maximum load and cross-section area, respectively.

\subsubsection{Differential Scanning Calorimetry}

The composite membrane (CM200:16) was analyzed using differential scanning calorimetry (DSC) in comparison with curcumin, piperine, HPBCD, a curcumin-HPBCD inclusion complex, and a blank composite membrane (BCM). The curcumin-HPBCD inclusion complex was prepared by dissolving HPBCD $(200 \mathrm{mg})$ in 50\% v/v ethanol $(10 \mathrm{~mL})$ followed by curcumin $(200 \mathrm{mg})$, and this sample was then dried in a hot air oven (UF 110, Memmert GmbH + Co. KG, Schwabach, Germany) at $60{ }^{\circ} \mathrm{C}$ for $4 \mathrm{~h}$, as was done in the composite membrane preparation. The analysis was performed in a heating range of 25-300 ${ }^{\circ} \mathrm{C}$ and a heating rate of $10^{\circ} \mathrm{C} / \mathrm{min}$ using a DSC 6000 (Perkin Elmer, Waltham, MA, USA).

\subsection{Curcumin and Piperine Content}

The content of curcumin and piperine in the composite membrane (CM200:16) was analyzed by the extraction method using ethanol. The composite membrane $(0.5 \times 0.5 \mathrm{~cm})$ was cut into small pieces $(\sim 0.1 \times 0.1 \mathrm{~cm})$, put into ethanol $(10 \mathrm{~mL})$, and sonicated at room temperature $\left(\sim 25^{\circ} \mathrm{C}\right)$ for $25 \mathrm{~min}$ to ensure all amount of curcumin and piperine was extracted from the composite membrane. Curcumin and piperine were analyzed using high performance liquid chromatography (HPLC) with Sepex GP-C18, $2.1 \times 100 \mathrm{~mm}$ as an analytical column. The mobile phase and wavelength for analysis of curcumin were $1 \%$ acetate buffer $\mathrm{pH} 3$ and acetonitrile at a 1:1 ratio and at $430 \mathrm{~nm}$, respectively, and those for piperine were $1 \%$ acetic acid $\mathrm{pH} 3$ and acetonitrile at a $3: 2$ ratio and at $340 \mathrm{~nm}$, respectively. The curcumin or piperine content (\%) was calculated using the equation

$$
\text { Curcumin / piperine content }(\%)=\frac{\text { Measured amount of curcu min/piperine }}{\text { Theoretical amount of curcu min/piperine }} \times 100
$$

\subsection{Stability of Curcumin in the Composite Membrane}

The stability of curcumin in the composite membrane (CM200:8) was evaluated in two conditions; $30 \pm 2{ }^{\circ} \mathrm{C}, 75 \pm 5 \% \mathrm{RH}$ and $40 \pm 2{ }^{\circ} \mathrm{C}, 75 \pm 5 \% \mathrm{RH}$, for three months. The composite membrane $(2.5 \times 2.5 \mathrm{~cm})$ was put in a glass vial, protected from light and stored in the stability chambers (HPP108, Memmert, Memmert GmbH + Co. KG, Schwabach, Germany) under controlled conditions. The content of curcumin remained in the composite membrane during the storage period was measured using the same method as described in Section 2.4 to evaluate stability.

\subsection{Release Study}

The release of curcumin and piperine from the composite membrane was studied with CM200:8 as a representative of the composite membrane to ensure that curcumin and piperine can release from the composite membrane in the desired condition using a modified Franz diffusion cell $(1 \mathrm{~cm}$ diameter, $2.5 \mathrm{~mL}$ receptor volume). The composite membrane $(2.5 \times 2.5 \mathrm{~cm})$ was placed between donor and receptor chambers and fixed with grease and clamps. Figure 1 shows the schematic of the modified Franz diffusion cell assembled for the release study. The phosphate buffer saline (PBS) pH 7.4 was used as a receptor medium that was stirred at $300 \mathrm{rpm}$ continuously. The phosphate buffer $\mathrm{pH} 5.5$ $(200 \mu \mathrm{L})$ was placed on the composite membrane in the donor phase. The temperature of the receptor phase was controlled at $37 \pm 1{ }^{\circ} \mathrm{C}$. Five hundred microliters of receptor medium were withdrawn and replaced with fresh medium at sampling times between 0 and $24 \mathrm{~h}$. The release profiles were obtained by measuring curcumin and piperine concentration by using a UV-vis spectrophotometer (UV-1800, Shimadzu, Tokyo, Japan) at 430 and $340 \mathrm{~nm}$, respectively. The lag time was obtained from 
extrapolating the line to the $x$-axis intersection and the diffusion coefficient (D) was calculated using the equation

$$
\mathrm{D}=\frac{\mathrm{Jx}}{\mathrm{C}}
$$

where $\mathrm{J}$ is the flux $\left(\mu \mathrm{g} / \mathrm{cm}^{2} / \mathrm{h}\right), \mathrm{x}$ is the membrane thickness $(\mathrm{cm})$, and $\mathrm{C}$ is the concentration $(\mu \mathrm{g} / \mathrm{mL})$.

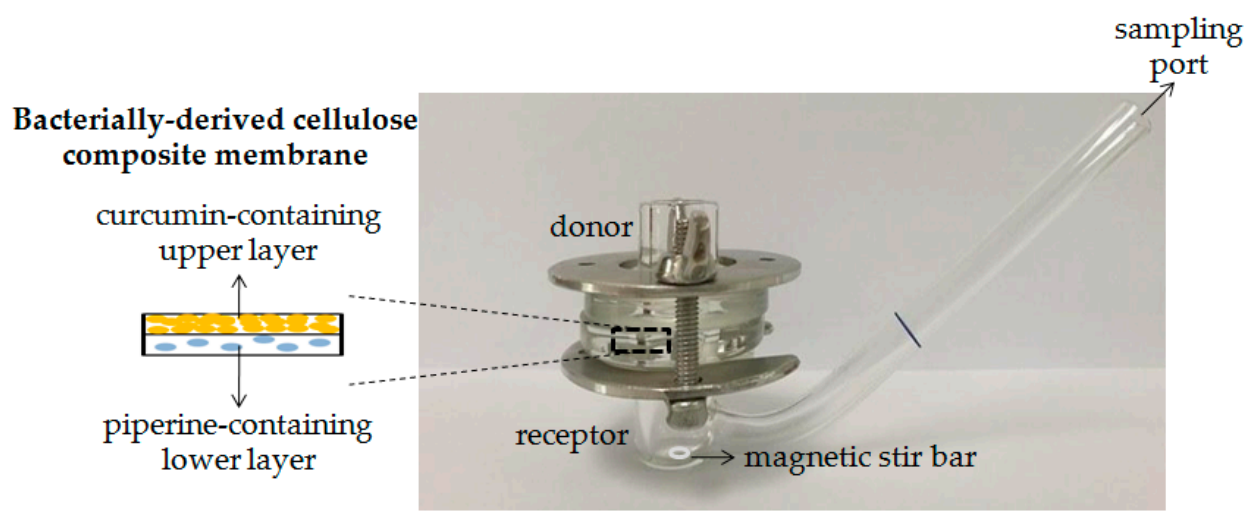

Figure 1. Schematic of the modified Franz diffusion cell assembled for release study.

\subsection{In Vitro Skin Permeation Study}

The skin permeation of curcumin and piperine from the composite membranes was studied using male mouse dorsal skin and the modified Franz diffusion cell $(1 \mathrm{~cm}$ diameter, $2.5 \mathrm{~mL}$ receptor volume). The experiment was carried out in accordance with the Animals for Scientific Purposes Act, B.E. 2558 (A.D. 2015), Thailand. The protocol was approved by the Ethical Committee for Animal Use of Walailak University (clearance no. 004/2013). The mouse dorsal skin was shaved and removed dermis and subcutaneous tissue, cut to a size of $2.5 \times 2.5 \mathrm{~cm}$, and placed between donor and receptor chambers of the mollified Franz diffusion cell. The composite membrane was cut to a size of $2.5 \times 2.5 \mathrm{~cm}$ and placed on the mouse skin. The lower layer (the piperine-containing layer) was attached to the skin. The modified Franz diffusion cell was assembled and fixed with grease and clamps. The receptor chamber was filled with the mixture of phosphate buffer saline (PBS), pH 7.4, and ethanol at a 1:1 ratio to obtain sink condition [30]. The receptor phase was controlled at $37 \pm 1{ }^{\circ} \mathrm{C}$ and continuously stirred at $300 \mathrm{rpm}$. The phosphate buffer pH $5.5(200 \mu \mathrm{L})$ was put on the composite membrane in the donor phase and closed with the cover slip. The receptor medium was withdrawn at sampling times between 0 and $24 \mathrm{~h}$ with fresh medium replaced. The concentration of curcumin and piperine was analyzed using HPLC as described in the curcumin and piperine content study. The graph between cumulative permeation of curcumin and piperine ( $y$-axis) and time ( $x$-axis) were plotted. The lag time and flux were obtained from the $x$-axis intersection and slope, respectively.

\section{Results}

\subsection{Preparation of Bacterially Derived Cellulose-Composite Membrane}

The bacterially derived cellulose-composite membrane as a double layer, with the lower layer composed of piperine and the upper layer composed of curcumin, was successfully prepared by the casting and solvent evaporation method. This form of system was designed in order to lead piperine released from the system and interacted with skin structure before curcumin would be released through the skin. The photograph of bacterially derived cellulose-composite membrane (CM200:8) is shown in Figure 2. The composite membrane was yellow-orange, smooth, and flexible and has a thickness of $0.08 \pm 0.02 \mathrm{~mm}$. 


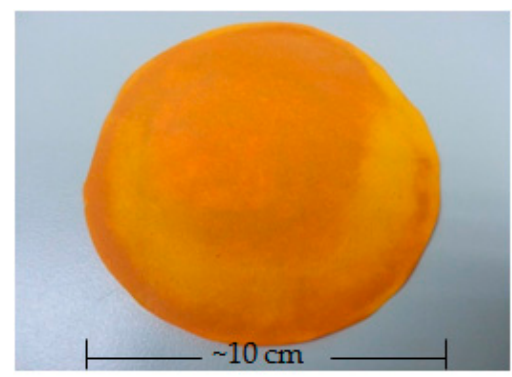

Figure 2. Photograph of bacterially derived cellulose-composite membrane (CM200:8).

In our preliminary study, it was found that the amount of bacterially derived cellulose and curcumin, the type of solvent and drying temperature affected the characteristics and successfulness for the composite membrane preparation. Too little or too much cellulose and too much curcumin led to a fragile, shrunk, or collapsed composite membrane. The optimum amount of bacterially derived cellulose was $15 \mathrm{~g}$, and the maximum amount of curcumin that could be loaded into membrane was $200 \mathrm{mg}$. The amount of piperine used in this study $(4-16 \mathrm{mg})$ was relatively low and therefore did not affect the characteristics of the composite membrane. In a previous study, the amount of piperine used as an oral enhancer for curcumin was about $1-4 \%[16,25]$. In this study, although the amount of piperine used $(1.96 \%-7.41 \%)$ was slightly higher, it was expected to remain suitable for use with the skin. To use absolute ethanol as a solvent in composite membrane preparation caused bubbles within the composite membrane. The $50 \% v / v$ ethanol $(5-10 \mathrm{~mL})$ was used instead because it could dissolve curcumin, piperine, and HPBCD completely and did not create bubble problems. All types of composite membranes prepared in this study were strong and flexible enough to use with skin without plasticizer.

\subsection{Physical Properties}

\subsubsection{Swelling and Tensile Strength}

Figure 3 shows the swelling degree and tensile strength of composite membranes containing different amounts of curcumin (CM100:4, CM150:8, and CM200:8) compared with the blank composite membrane $(\mathrm{BCM})$. The swelling degree of the $\mathrm{BCM}$ was higher than that of composite membranes. As the amount of curcumin increased, the swelling of the composite membrane decreased accordingly. The swelling degree of the BCM $(799.25 \pm 44.65 \%)$ was higher than that of the native air-dried bacterially derived cellulose membrane, which has been reported in the literature (269.8\%) [31]. This might be due to the alignment of the cellulose in the native one was more compact. The process of composite membrane preparation was not affected to the swelling property of bacterially derived cellulose. The bacterially derived cellulose was tolerant to ethanol and a temperature of $\sim 60{ }^{\circ} \mathrm{C}$ for at least $6 \mathrm{~h}$. The decrease in swelling degree of the composite membrane when curcumin was added might be because curcumin particles were inserted within cellulose fibers; therefore, the porosity of the composite membrane decreased as a barrier to the infiltration of the water. As the curcumin content increased, the degree of swelling of the composite membrane decreased. Although the highest amount of curcumin-loaded $(200 \mathrm{mg}$ ) composite membrane gave about a twofold lower swelling degree $(435.07 \pm 115.36 \%)$ than did the BCM, its swelling degree was considered high enough and suitable for use for human skin applications.

The tensile strength of the composite membranes when compared with the BCM was obtained with a behavior similar to that of the swelling. The highest value of the tensile strength was obtained in the BCM, and the value decreased when curcumin was included. The tensile strength of the BCM was $124.42 \pm 16.97 \mathrm{MPa}$, which was lower than that of the native bacterially derived cellulose, reported to be as high as $400 \mathrm{MPa}$ [32]. This could be because the bacterially derived cellulose fibers were blended before they were reformed as a composite membrane, resulting in lower tensile strength behavior. When curcumin was included in the composite membrane, it would interrupt the formation of the 
composite membrane. The tensile strengths of all three types of composite membranes were not much different from each other and were within the range of 15-22 $\mathrm{MPa}$. This implied that the amount of curcumin in the range of 100-200 mg slightly affects the tensile strength of the composite membranes. The composite membrane containing the highest amount of curcumin at $200 \mathrm{mg}$ was considered strong enough to be handled and used for skin.

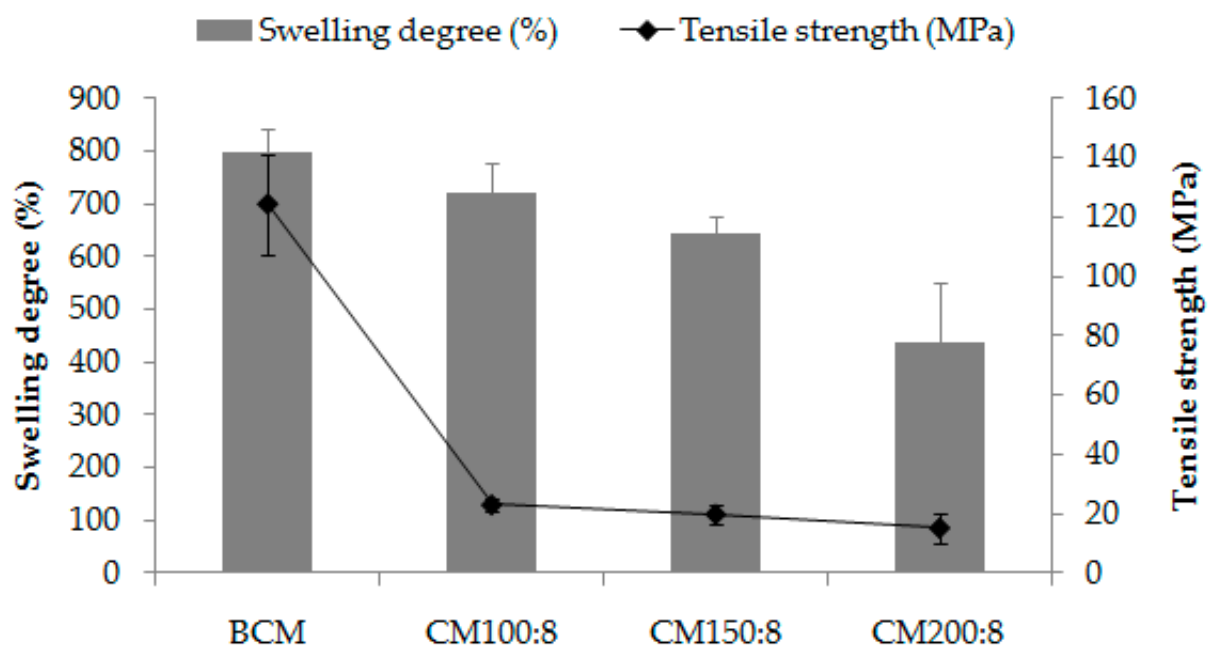

Type of composite membrane

Figure 3. Swelling degree (\%) and tensile strength (MPa) of composite membranes containing different amounts of curcumin (CM100:8, CM150:8, and CM200:8) compared with the blank composite membrane (BCM).

\subsubsection{Differential Scanning Calorimetry}

Figure 4 shows differential scanning calorimetry (DSC) thermograms of the composite membrane (CM200:16) compared with the composition of each substance (curcumin, piperine, and HPBCD) and the blank composite cellulose (BCM) to assess whether there is chemical interaction between substances. It was found that curcumin and piperine showed one sharp endothermic peak at 177.63 and $133.20^{\circ} \mathrm{C}$, respectively, which reflected their melting point. HPBCD and the BCM showed broad endothermic peaks around 115.75 and $97.96^{\circ} \mathrm{C}$, respectively. The curcumin-HPBCD inclusion complex showed two peaks around 175.43 and $114.26{ }^{\circ} \mathrm{C}$. They were slightly different with that of pure substances. This might be because the chemical interaction occurred between these two compounds according to the inclusion complex. The chemical interaction for the inclusion complex between cyclodextrin and curcumin may include a van der Waals interaction, hydrogen bonding, and hydrophobic interaction [33]. This implies that common solvent evaporation could produce a curcumin-HPBCD inclusion complex, which complies with a previous study [34]. The DSC thermograms of the composite membrane showed a small peak in accordance with curcumin and a small broad peak in accordance with the bacterially derived cellulose and the HPBCD, but a peak in accordance with piperine was not observed. This result could confirm the presence of curcumin in the composite membrane but piperine content was too low to be observed by DSC. 


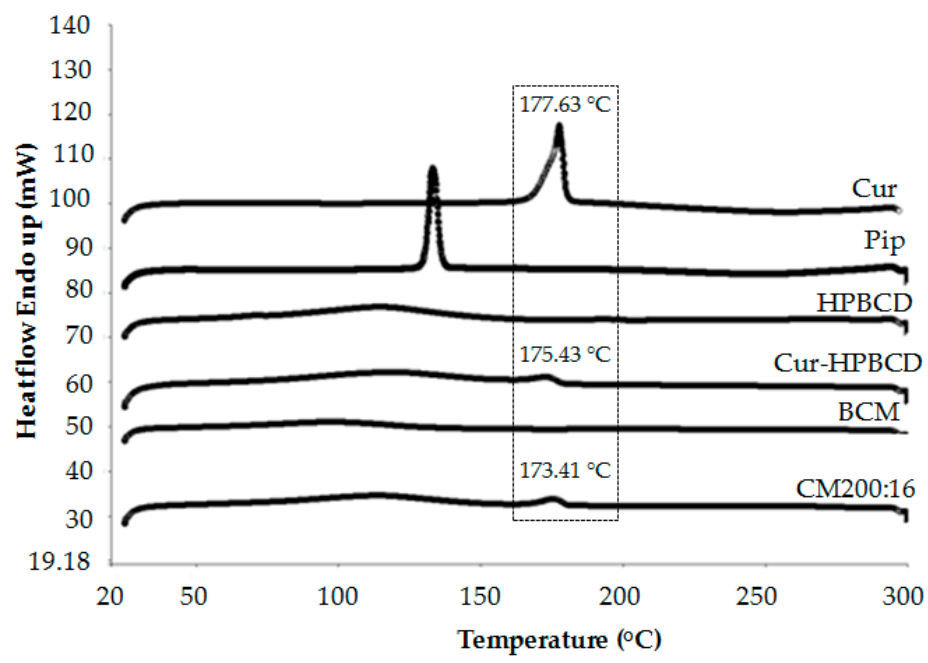

Figure 4. Differential scanning calorimetry (DSC) thermograms of the composite membrane (CM200:16) in comparison with curcumin (Cur), piperine (Pip), hydroxypropyl- $\beta$-cyclodextrin (HPBCD), curcumin-hydroxypropyl- $\beta$-cyclodextrin inclusion complex (Cur-HPBCD), and a blank composite membrane (BCM).

\subsection{Curcumin and Piperine Content}

From the curcumin and piperine content study, it was found that the content of curcumin and piperine in the composite membrane were $94.99 \pm 4.11 \%$ and $98.52 \pm 2.53 \%$, respectively. This result implies that the preparation method can yield a high amount of drug loading $(>90 \%)$ and the preparation process resulted in less drug loss. Moreover, curcumin and piperine had good stability in the solvent used and under drying temperature $\left(60^{\circ} \mathrm{C}\right)$ during composite membrane preparation.

\subsection{Stability of Curcumin in the Composite Membrane}

Figure 5 shows that curcumin content remained in the composite membrane after being stored at $30 \pm 2{ }^{\circ} \mathrm{C}, 75 \pm 5 \% \mathrm{RH}$, and $40 \pm 2{ }^{\circ} \mathrm{C}, 75 \pm 5 \% \mathrm{RH}$ for 3 months. Curcumin content remained higher than $90 \%$ for both conditions. The impact of $\mathrm{pH}$, temperature, and molecular environment on the stability of curcumin is generally known [35]. One way to increase the stability of curcumin is to form an inclusion complex with cyclodextrin [34]. The high stability of curcumin in the composite membrane could be from the inclusion complex with HPBCD within the composite membrane, together with the storage condition as in normal temperature and protected from light.

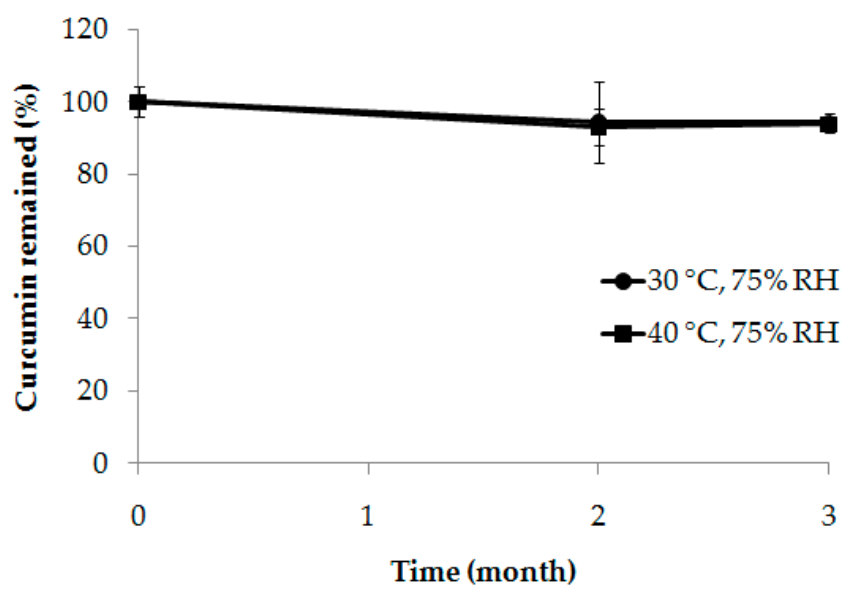

Figure 5. The remaining curcumin in the composite membrane (CM200:8) after being stored at $30 \pm 2{ }^{\circ} \mathrm{C}, 75 \pm 5 \% \mathrm{RH}$, and $40 \pm 2{ }^{\circ} \mathrm{C}, 75 \pm 5 \% \mathrm{RH}$ for 1,2 , and 3 months. 


\subsection{Release Study}

Figure 6 shows the release profiles of curcumin and piperine from the composite membrane in PBS pH 7.4 at $37 \pm 1{ }^{\circ} \mathrm{C}$. It was found that curcumin and piperine could be released from the composite membrane as time increased. Curcumin was released relatively quickly in the first three hours. This might be due to some curcumin sticking on the outside of the composite membrane. After three hours, curcumin was gradually increased. The total amount of curcumin released at $24 \mathrm{~h}$ $(\sim 70 \%)$ was not completed. This might be due to the difficulty of curcumin released from the upper layer of the composite membrane. It required time and distance to pass through the lower layer before reached the receptor medium of the modified Franz diffusion cell. Although curcumin had low solubility $(0.6 \mu \mathrm{g} / \mathrm{mL})$ [36], the curcumin-HPBCD inclusion complex could increase curcumin's solubility by about 188 times [34]. This reason allowed curcumin to release from the composite membrane to the dissolution medium.

Piperine was released relatively quickly in the first three hours to obtain about $60 \%$ and gradually released until completed $(102.69 \pm 17.02 \%)$ at $12 \mathrm{~h}$. This is because piperine had relatively high solubility $(0.164 \mathrm{mg} / \mathrm{mL})$ [37] compared with curcumin $(0.6 \mu \mathrm{g} / \mathrm{mL})$ [36], and the lower layer containing piperine directly contacted the buffer in the receptor phase of the modified Franz diffusion cell. The rapid and complete release of piperine from the composite membrane would be benefited via interaction with the skin structure before curcumin would be delivered through the skin.

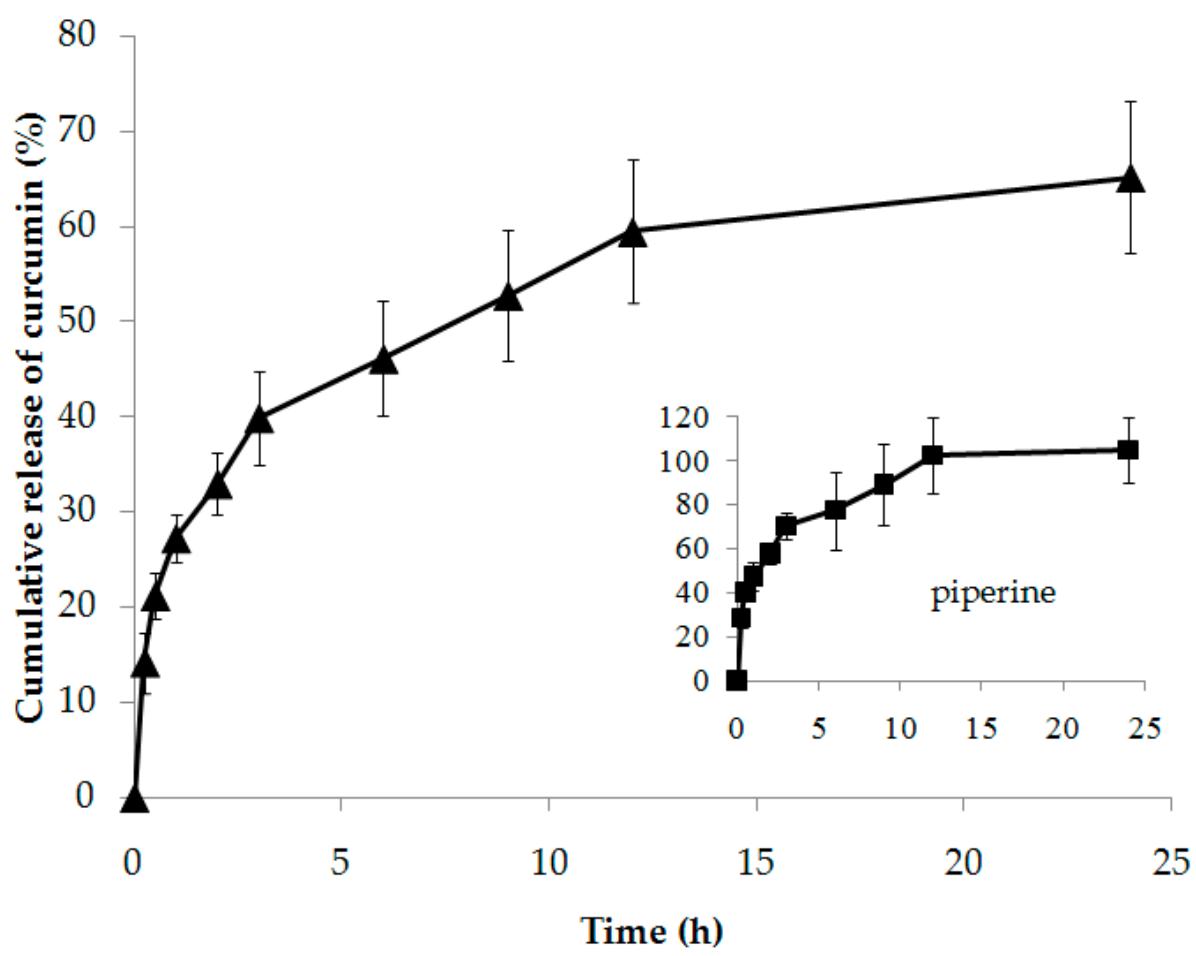

Figure 6. Release profiles of curcumin and piperine from composite membrane (CM200:8) in PBS pH 7.4 at $37 \pm 1{ }^{\circ} \mathrm{C}$.

The lag time and diffusion coefficient (D) of curcumin and piperine are shown in Table 2. It was found that the lag time of curcumin $(0.56 \pm 0.46 \mathrm{~h})$ was slightly slower than that of piperine $(0.47 \pm 0.41 \mathrm{~h})$. This meant that piperine was released from the composite membrane faster than curcumin was. The $\mathrm{D}$ value of piperine $(8.17 \pm 0.87 \mathrm{~mm} / \mathrm{s})$ was about 30 times higher than that of curcumin $(0.27 \pm 0.04 \mathrm{~mm} / \mathrm{s})$. This meant that piperine moves through the composite membrane at a much faster rate than curcumin. 
Table 2. Lag time (h) and diffusion coefficient (D) of curcumin and piperine released from the composite membrane (CM200:8) in PBS pH 7.4 at $37 \pm 1^{\circ} \mathrm{C}$.

\begin{tabular}{ccc}
\hline Substance in CM200:8 & Lag Time (h) & D (mm/s) \\
\hline Curcumin & $0.56 \pm 0.46$ & $0.27 \pm 0.04$ \\
Piperine & $0.47 \pm 0.41$ & $8.17 \pm 0.87$ \\
\hline
\end{tabular}

\subsection{In Vitro Skin Permeation Study}

In this study, the effect of piperine on the skin permeation of curcumin from composite membranes was investigated. The amount of curcumin contained in the composite membrane was fixed at $200 \mathrm{mg}$, but the amount of piperine was different, with 0, 4, 8, and $16 \mathrm{mg}$ (with CCM, CM200:4, CM200:8, CM200:16), i.e., $0,1.96,3.85$, and $7.41 \%$, respectively. The permeation profiles of the curcumin and piperine are shown in Figure 7. It was found that, when the amount of piperine increased, the trend of the permeation of the curcumin was increased. The difference of curcumin permeation could be clearly observed from $6 \mathrm{~h}$ onwards. Piperine is a well-known bioenhancer for oral drug delivery including curcumin, but for transdermal drug delivery it had little information. Piperine has been explored as bioenhancer for transdermal delivery of aceclofenac that could enhance drug permeation by about 2-8 times when using about $0.5-2 \%$ [27]. The mechanism of piperine to enhance skin permeation of drugs possibly involves partial extraction of the stratum corneum, interaction with the keratin of the stratum corneum, tight junction protein disruption, and the intercalation complex of piperine and curcumin $[28,29]$.

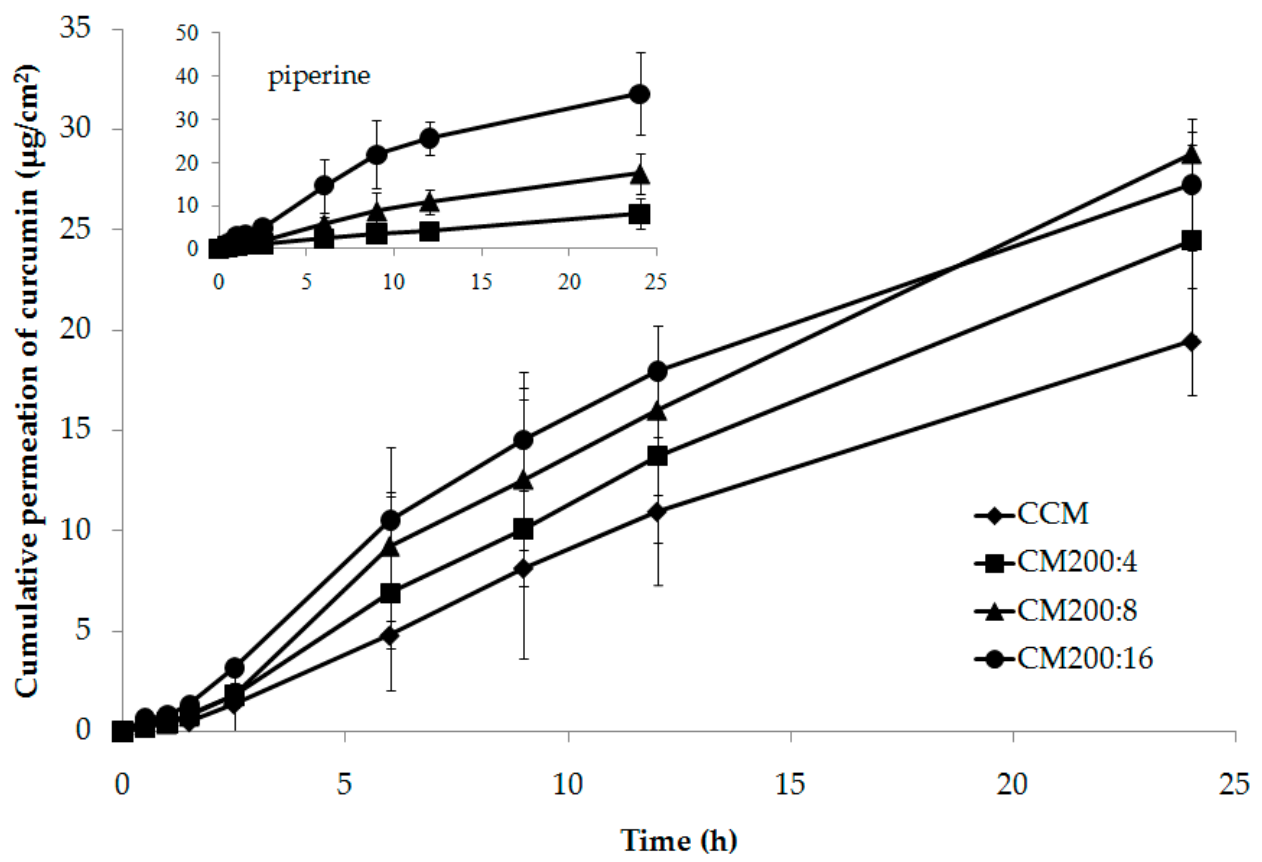

Figure 7. Permeation profiles of curcumin and piperine from different composite membranes compared with controlled composite membrane through mouse dorsal skin.

Table 3 shows the lag time and flux (J) of curcumin and piperine released from the composite membranes and permeated through the mouse skin. Piperine would be expected to have shorter lag time because it was contained in the lower layer of the composite membrane. However, the result showed that the lag times of both compounds were not different. This might be due to curcumin sticking on the outside of the composite membrane, ready to be released along with piperine. Another reason might be the use of the mouse skin, which is rather thin. The substances would therefore move through the skin easily, and differences in lag time would rarely be observed. 
Table 3. Lag time and flux (J) of curcumin and piperine from different composite membranes compared with controlled composite membrane through mouse dorsal skin.

\begin{tabular}{ccccc}
\hline \multirow{2}{*}{ Type of Composite Membrane } & \multicolumn{2}{c}{ Lag Time (h) } & \multicolumn{2}{c}{$\mathbf{J}\left(\boldsymbol{\mu g} / \mathrm{cm}^{2} / \mathbf{h}\right)$} \\
\cline { 2 - 5 } & Curcumin & Piperine & Curcumin & Piperine \\
\hline CCM & $1.90 \pm 0.63$ & - & $4.29 \pm 1.70$ & - \\
CM200:4 & $2.62 \pm 0.63$ & $2.78 \pm 1.98$ & $5.51 \pm 1.87$ & $2.30 \pm 1.37$ \\
CM200:8 & $2.46 \pm 0.36$ & $2.54 \pm 1.12$ & $6.93 \pm 0.76$ & $7.03 \pm 1.72$ \\
CM200:16 & $1.91 \pm 0.41$ & $1.99 \pm 0.99$ & $8.10 \pm 1.51$ & $17.99 \pm 8.87$ \\
\hline
\end{tabular}

The rate of movement of the substances from the composite membrane through the skin is represented as the flux. The flux value of piperine from the composite membranes correlated with the amount of piperine added. The amount of piperine that increased twofold caused a flux increase by about 2.5 times. The highest flux of piperine was obtained from CM200:16, with a value of $17.99 \pm 8.78 \mu \mathrm{g} / \mathrm{cm}^{2} / \mathrm{h}$. The flux of curcumin increased with the increase in the amount of piperine. The composite membranes containing piperine yielded flux values higher than those of the non-piperine-containing composite membrane (BCM). The amount of piperine added to the composite membrane as $1.96 \%, 3.85 \%$, and $7.41 \%$ caused the flux of curcumin to increase by 1.28 , 1.62 and 1.89 times, respectively, compared to the BCM. Although the effect of piperine on the skin permeation of curcumin was not very high, it could be confirmed that piperine, especially at $3.85 \%$ and $7.41 \%$, significantly enhanced the skin permeation of curcumin. In order to enhance skin permeation of this system, technologies that could facilitate transdermal administration such as phonophoresis should be used in conjunction with a skin permeation enhancer.

In previous studies, piperine has been used as a transdermal enhancer for several drugs $[26,27]$ but it has not been used for curcumin. The permeation of curcumin when used in combination with piperine was $2-8$ times higher than that of curcumin alone. This may be because piperine has different effects on each drug. To our knowledge, this is the first study to investigate the effect of piperine as a transdermal enhancer for curcumin. The type of skin used in the in vitro permeation study may also affect the results. The mechanism that enhances skin permeation is related to change in skin structure [28]. Mouse skin is rather thin and, compared to rat or human skin, generally contains fewer structural components. Piperine, therefore, has a lower chance of involving skin structure. One mechanism of piperine that enhances skin permeation involves an increase in blood supply. This mechanism cannot occur in in vitro studies. This would be a limitation of in vitro permeation studies for piperine evaluation. Dermal penetration can be influenced by a number of factors. Basak et al. reported that molecular size factors and hydrophobicity play the most important roles in dermal penetration [38].

\section{Conclusions}

In this study, piperine used as a bioenhancer for transdermal curcumin delivery was investigated in vitro using mouse skin. The delivery system in the form of bacterially derived composite membrane as a double layer, containing curcumin and hydroxypropyl- $\beta$-cyclodextrin in the upper layer and piperine in the lower layer, was successfully prepared. This design was intended to allow piperine to interact with the skin structure before curcumin passed through. The amount of curcumin added in the composite membrane caused the swelling and tensile strength properties of the composite membrane to decrease; however, the amount of curcumin used-up to $200 \mathrm{mg}$ - and the amount of piperine used-16 $\mathrm{mg}$ - for a $78.57 \mathrm{~cm}^{2}$ composite membrane still provided a suitable composite membrane for use. Piperine had an effect on the increase in skin permeation of curcumin in vitro through mouse skin and its effect was related to the amount added into the composite membrane. The composite membrane containing piperine at $7.41 \%$ could increase skin permeation of curcumin by about 1.89 times. In vivo skin permeation is recommended for further study because one possible mechanism of piperine as a skin permeation enhancer would be associated with increased blood 
supply to the skin; therefore, a greater enhancement effect would be observed. Moreover, the skin irritation of piperine-containing systems should be studied.

Author Contributions: Conceptualization, C.J. and P.S.; Methodology, C.J.; Formal analysis, C.J. and P.S.; Investigation, S.B., W.M. and H.W.; Writing-original draft, C.J.

Funding: This research was funded by Walailak University (WU56311).

Acknowledgments: The authors would like to thank Chitnarong Sirisathitkul for advice on the preparation of the manuscript.

Conflicts of Interest: The authors declare no conflict of interest.

\section{References}

1. National List of Essential Medicines, 2018-Thailand. Available online: http:/ /www.ratchakitcha.soc.go.th/ DATA/PDF/2561/E/014/4.PDF (accessed on 8 July 2018).

2. Priyadarsini, K.I. The Chemistry of Curcumin: From extraction to therapeutic agent. Molecules 2014, 19, 20091-20112. [CrossRef] [PubMed]

3. Maheshwari, R.K.; Singh, A.K.; Gaddipati, J.; Srimal, R.C. Multiple biological activities of curcumin: A short review. Life Sci. 2006, 78, 2081-2087. [CrossRef] [PubMed]

4. Gupta, S.C.; Patchva, S.; Koh, W.; Aggarwal, B. Discovery of curcumin, a component of the golden spice, and its miraculous biological activities. Clin. Exp. Pharmacol. Physiol. 2012, 39, 283-299. [CrossRef] [PubMed]

5. Amalraj, A.; Pius, A.; Gopi, S.; Gopi, S. Biological activities of curcuminoids, other biomolecules from turmeric and their derivatives: A review. J. Tradit. Complement. Med. 2017, 7, 205-233. [CrossRef] [PubMed]

6. Vareed, S.K.; Kakarala, M.; Ruffin, M.T.; Crowell, J.A.; Normolle, D.P.; Djuric, Z.; Brenner, D.E. Pharmacokinetics of curcumin conjugate metabolites in healthy human subjects. Cancer Epidemiol. Biomark. Prev. 2008, 17, 1411-1417. [CrossRef] [PubMed]

7. Kumar, S.; Kesharwani, S.S.; Mathus, H.; Tyagi, M.; Bhat, G.J.; Tummala, H. Molecular complexation of curcumin with $\mathrm{pH}$ sensitive cationic copolymer enhances the aqueous solubility, stability and bioavailability of curcumin. Eur. J. Pharm. Sci. 2016, 82, 86-96. [CrossRef] [PubMed]

8. Wahlang, B.; Pawar, Y.B.; Bansal, A.K. Identification of permeability-related hurdles in oral delivery of curcumin using the Caco-2 cell model. Eur. J. Pharm. Biopharm. 2011, 77, 275-282. [CrossRef] [PubMed]

9. Sharma, R.A.; Steward, W.P.; Gescher, A.J. Pharmacokinetics and pharmacodynamics of curcumin. Adv. Exp. Med. Biol. 2007, 595, 453-470. [PubMed]

10. Prasad, S.; Tyagi, A.; Aggarwal, B. Recent developments in delivery, bioavailability, absorption and metabolism of curcumin: The golden pigment from golden spice. Cancer Res. Treat. 2014, 46, 2-18. [CrossRef] [PubMed]

11. Pathan, I.B.; Jaware, B.P.; Shelke, S.; Ambekar, W. Curcumin loaded ethosomes for transdermal application: Formulation, optimization, in-vitro and in-vivo study. J. Drug Deliv. Sci. Technol. 2018, 44, 49-57. [CrossRef]

12. Angelova, A.; Garamus, V.M.; Angelov, B.; Tian, Z.; Li, Y.; Zou, A. Advances in structural design of lipid-based nanoparticle carriers for delivery of macromolecular drugs, phytochemicals and anti-tumor agents. Adv. Colloid Interface Sci. 2017, 249, 331-345. [CrossRef] [PubMed]

13. Guerzoni, L.P.; Nicolas, V.; Angelova, A. In Vitro Modulation of TrkB Receptor Signaling upon Sequential Delivery of Curcumin-DHA Loaded Carriers Towards Promoting Neuronal Survival. Pharm. Res. 2017, 34, 492-505. [CrossRef] [PubMed]

14. Kesarwani, K.; Gupta, R. Bioavailability enhancers of herbal origin: An overview. Asian Pac. J. Trop. Biomed. 2013, 3, 253-266. [CrossRef]

15. Atal, C.K. A breakthrough in drug bioavailability: A clue from age old wisdom of Ayurveda. I.D.M.A. Bull. 1979, 10, 483-484.

16. Shaikh, J.; Ankola, D.D.; Beniwal, V.; Singh, D.; Kumar, M.N. Nanoparticle encapsulation improves oral bioavailability of curcumin by at least 9-fold when compared to curcumin administered with piperine as absorption enhancer. Eur. J. Pharm. Sci. 2009, 37, 223-230. [CrossRef] [PubMed]

17. Moorthi, C.; Krishnan, K.; Manavalan, R.; Kathiresan, K. Preparation and characterization of curcumin-piperine dual drug loaded nanoparticles. Asian Pac. J. Trop. Biomed. 2012, 2, 841-848. [CrossRef] 
18. Boddupalli, B.M.; Anisetti, R.N.; Mamani, R.; Malothu, N. Enhanced pharmacokinetics of omeprazole when formulated as gastroretentive microspheres along with piperine. Asian Pac. J. Trop. Dis. 2014, 1, S129-S133. [CrossRef]

19. Di, X.; Wang, X.; Di, X.; Liu, Y. Effect of piperine on the bioavailability and pharmacokinetics of emodin in rats. J. Pharm. Biomed. Anal. 2015, 115, 144-149. [CrossRef] [PubMed]

20. Cherniakov, I.; Izgelov, D.; Barasch, D.; Davidson, E.; Domb, A.J.; Hoffman, A. Piperine-pro-nanolipospheres as a novel oral delivery system of cannabinoids: Pharmacokinetic evaluation in healthy volunteers in comparison to buccal spray administration. J. Control. Release 2017, 266, 1-7. [CrossRef] [PubMed]

21. Baspinar, Y.; Ustundas, M.; Bayraktar, O.; Zezgin, C. Curcumin and piperine loaded zein-chitosan nanoparticles: Development and in-vitro characterization. Saudi Pharm. J. 2018, 26, 323-334. [CrossRef] [PubMed]

22. Jin, Z.H.; Qiu, W.; Liu, H.; Jiang, X.H.; Wang, L. Enhancement of oral bioavailability and immune response of Ginsenoside Rh2 by co-administration with piperine. Chin. J. Nat. Med. 2018, 16, 143-149. [CrossRef]

23. Khajuria, N.; Zutshi, U. Piperine modulates permeability characteristics of intestine by inducing alterations in membrane dynamics: Influence on brush border membrane fluidity, ultrastructure and enzyme kinetics. Phytomedicine 2002, 9, 224-231. [CrossRef] [PubMed]

24. Atal, N.; Bedi, K.L. Bioenhancers: Revolutionary concept to market. J. Ayurveda Integr. Med. 2010, 1, 96-99. [CrossRef] [PubMed]

25. Shoba, G.; Joy, D.; Joseph, T.; Majeed, M.; Rajendran, R.; Srinivas, P.S. Influence of piperine on the pharmacokinetics of curcumin in animals and human volunteers. Planta Med. 1998, 64, 353-356. [CrossRef] [PubMed]

26. Kaushal, N.; Jain, S.; Kondaiah, P.; Tiwary, A.K. Influence of piperine on transcutaneous permeation of repaglinide in rats and on tight junction proteins in $\mathrm{HaCaT}$ cells: Unveiling the mechanisms for enhanced permeation. Sci. Pharm. 2009, 77, 877-897. [CrossRef]

27. Shah, K.K.; Shiradkar, M.R.; Bindu, V.H. Transdermal delivery of aceclofenac: Effect of piperine and itsmechanism of action. Int. J. Pharma Bio Sci. 2011, 2, 10-18.

28. Das, A.; Ahmed, A.B. Natural permeation enhancer for transdermal drug delivery system and permeation evaluation: A review. Asian J. Pharm. Clin. Res. 2017, 10, 5-7. [CrossRef]

29. Patil, V.M.; Das, S.; Balasubramanian, K. Quantum chemical and docking insights into bioavailability enhancement of curcumin by piperine in pepper. J. Phys. Chem. A 2016, 120, 3643-3653. [CrossRef] [PubMed]

30. Liu, C.H.; Chang, F.Y.; Hung, D.K. Terpene microemulsions for transdermal curcumin delivery: Effects of terpenes and cosurfactants. Colloids Surf. B Biointerfaces 2011, 82, 63-70. [CrossRef] [PubMed]

31. Tsai, Y.H.; Yang, Y.N.; Ho, Y.C.; Tsai, M.L.; Mi, F.L. Drug release and antioxidant/antibacterial activities of silymarin-zein nanoparticle/bacterial cellulose nanofiber composite films. Carbohydr. Polym. 2018, 180, 286-296. [CrossRef] [PubMed]

32. Qui, Y.; Qiu, L.; Cui, J.; Wei, Q. Bacterial cellulose and bacterial cellulose-vaccarin membranes for wound healing. Mater. Sci. Eng. C Mater. Biol. Appl. 2016, 59, 303-309.

33. Yadav, V.R.; Suresh, S.; Devi, K.; Yadav, S. Effect of cyclodextrin complexation of curcumin on its solubility and antiangiogenic and anti-inflammatory activity in rat colitis model. AAPS PharmSciTech. 2009, 10, 752-762. [CrossRef] [PubMed]

34. Jantarat, C.; Sirathanarun, P.; Ratanapongsai, S.; Watcharakan, P.; Sunyapong, S.; Wadu, A. Curcumin-hydroxypropyl- $\beta$-cyclodextrin inclusion complex preparation methods: Effect of common solvent evaporation, freeze drying, and $\mathrm{pH}$ shift on solubility and stability of curcumin. Trop. J. Pharm. Res. 2014, 13, 1215-1223. [CrossRef]

35. Kharat, M.; Du, Z.; Zhang, G.; McClements, D.J. Physical and chemical stability of curcumin in aqueous solutions and emulsions: Impact of $\mathrm{pH}$, temperature, and molecular environment. J. Agric. Food Chem. 2017, 65, 1525-1532. [CrossRef] [PubMed]

36. Shin, G.H.; Li, J.; Cho, J.H.; Kim, J.T.; Park, H.J. Enhancement of curcumin solubility by phase change from crystalline to amorphous in cur-TPGS nanosuspension. J. Food Sci. 2016, 81, N494-N501. [CrossRef] [PubMed] 
37. Shao, B.; Cui, C.; Ji, H.; Tang, J.; Wang, Z.; Liu, H.; Qin, M.; Li, X.; Wu, L. Enhanced oral bioavailability of piperine by selfemulsifying drug delivery systems: In vitro, in vivo and in situ intestinal permeability studies. Drug Deliv. 2015, 22, 740-747. [CrossRef] [PubMed]

38. Basak, S.C.; Mills, D.; Mumtaz, M.M. A quantitative structure-activity relationship (QSAR) study of dermal absorption using theoretical molecular descriptors. SAR QSAR Environ. Res. 2007, 18, 45-55. [CrossRef] [PubMed]

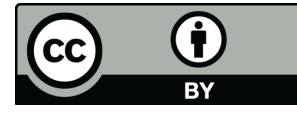

(C) 2018 by the authors. Licensee MDPI, Basel, Switzerland. This article is an open access article distributed under the terms and conditions of the Creative Commons Attribution (CC BY) license (http://creativecommons.org/licenses/by/4.0/). 